\title{
Seeing sense
}

\section{A look back at work that established the link between eye and brain.}

\section{Brain and Visual Perception: The Story of a 25-Year Collaboration by David H. Hubel \& Torsten N. Wiesel Oxford University Press: 2004. 738 pp. $\$ 49.50, £ 29.99$}

\section{Charles G. Gross}

In 1959, two postdoctoral fellows, a Canadian and a Swede working together at Johns Hopkins University, made an 'accidental discovery'. They found that the image of an edge of a glass slide activated cells in the region of a cat's brain known as the striate cortex. Over the next 25 years, David Hubel and Torsten Wiesel expanded their observation into some of the most important developments in understanding sensory physiology, sensory psychology and the functional architecture of the cerebral cortex since E. A. Adrian initiated modern sensory neurophysiology some 75 years ago.

Hubel and Wiesel outlined a scheme for the hierarchical processing of visual information that became the frame for all subsequent work in visual neurophysiology, as well as a model for other sensory systems. They provided the first possibility of a bridge from the eye to the cognitive science of pattern recognition. Their work included the first experimental demonstration that normal experience sculpts the anatomy and physiology of the brain. They also carried out the first experimental examination of the relative role of experience and innate wiring in the development of the neural mechanisms of perception and behaviour.

Almost uniquely among basic neuroscience researchers, Hubel and Wiesel made a discovery that was immediately transferred to the clinic, in this case saving binocular vision for children born with strabismus ('crossed' or 'wall' eyes). Their experiments were so simple and elegant that they had no use for computers or elaborate apparatus, and their results were so clean that no statistics were needed. They did all this and more, essentially with their own hands and without the help of graduate students, postdocs or an army of technicians. They received a Nobel prize for their work in 1981.

The bulk of this book consists of reproductions of 28 of Hubel and Wiesel's most important papers. The book begins with autobiographical essays by both men. The rest of the book is written by Hubel, but the 'we' that he uses is very much a collaborative rather than a royal one.

The autobiographies are followed by several short background chapters. One, too brief and forgiving, describes the state of cortical physiology when Hubel and Wiesel began their work. The retinotopic organization of striate cortex was understood from mapping studies in cats and monkeys done by Wade Marshall and S. A. Talbot in the 1940s, but nothing was known of the response properties of individual striate-cortex neurons.
In 1953 there were two demonstrations concerning cells in the frog's retina that could analyse complex form, one by Horace Barlow and one by Steve Kuffler, who was to become Hubel and Wiesel's postdoctoral adviser. These studies provided the starting point for Hubel and Wiesel's investigations of the cat's visual cortex in 1959, and probably sensitized the pair to the importance of the observation described in the opening of this review. Serendipity requires a prepared mind.

At about the same time, the work of Barlow and Kuffler was extended by Jerry Lettvin and Humberto Maturana in their paper 'What the frog's eye tells the frog's

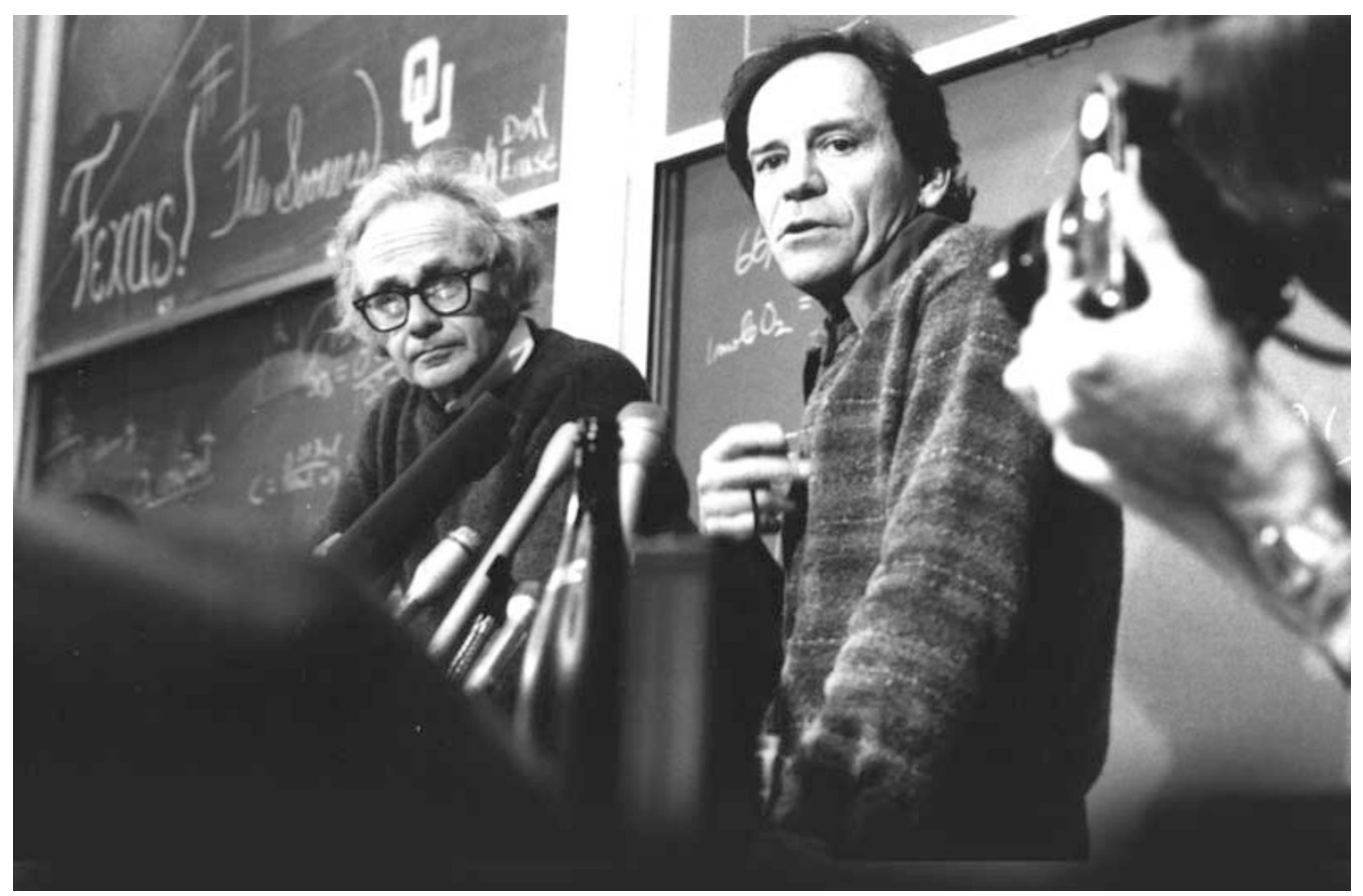

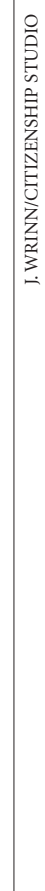

(left) and Torsten Wiesel won a Nobel prize for their work in 1981.

Other recording studies of striate cortex at this time usually used electrical stimulation of the optic nerve, rather than discrete visual stimuli.

By the 1950s, techniques for single-neuron recording in the striate cortex had been established by groups in Montreal in Canada and Freiburg in Germany. Yet both groups usually used only diffuse illumination as the visual stimulus, and this elicited only feeble responses. Eventually the Freiburg group started using an elaborate apparatus that could move a grid across the visual field, but only in a vertical orientation, making the discovery of orientation selectivity impossible. The only responses they found were variations of the 'on', 'off' and 'on/off' responses described by the Nobel laureate H. Keffer Hartline some 40 years earlier. brain'. Hubel and Wiesel were impressed when Lettvin showed them his complex frog neurons. The pair realized they"obviously had much in common with Lettvin and Maturana, especially our exploratory approach and freedom from complex apparatus, hypothesis, and so on. Jerry and Humberto carried their unusual approach to extremes, perhaps because they lacked an adviser like Steve who insisted we make at least a few measurements for the sake of scientific respectability."

The remaining background chapters in this book are largely a glowing tribute to Kuffler, Hubel and Wiesel's mentor, friend and protector, who died in 1980 . He brought them together at Johns Hopkins, encouraged them in every way, and took them to Harvard. Beyond this, Kuffler provided a lifelong model of doing science with your own hands, 
writing and rewriting over and over, and leaving your graduate students alone.

Perhaps the most interesting parts of the book are those that surround each paper or set of related papers. The forewords describe why they did each experiment. Then they describe what they did right and wrong, and comment a little (actually, very little) on subsequent developments in the field. Best of all, these parts, and the introductory chapters, are peppered with incidental remarks on how (and how not) to do science.

For example, on grants they say that much of their research "can be described as a massive fishing expedition, an expression commonly used by study sections to disparage bad grant requests". Their research, they explain, was seldom hypothesis driven. "But the lack of a hypothesis need not necessarily prevent one from catching big fish."

On computation: an example of the "illnesses" that can afflict science is an increase in "a theory sometimes called computation ... molecular biology, which we regard as more successful as a science than our field, seems largely to have avoided being beset with computation. In The Molecular Biology of the Gene I look in vain for equations."

On doing experiments, they write: "Unlike much of today's science, in which the actual work is done by technicians or graduate students ... it is we who get to do the experiments."

Hubel says he saves time by reading as little as possible in his field: "Reading most papers today is like eating sawdust.” He also says the pair benefited from their "refusal to waste time bothering with measuring intensities, rates of movement, and so on, or to spend time drawing graphs or histograms."

On statistics: "We could hardly get excited about an effect so feeble as to require statistics for its demonstration." And on failing to notice the directional properties of MT cells despite recording from about 200 of them: "We were lazy and not very bright."

There are two subjects on which I would have liked to see more. The first is their students: who were they, what did they work on, and how were they mentored? Perhaps they were just left alone. There is more about how Kuffler helped the duo than how they treated their own students.

The other subject is how the two collaborators actually worked together. One disagreement is obliquely referred to without explaining what it was. They speak of bulging files of 30 years of experimental protocols, a folder for each experiment. It would have been instructive to include some examples of these protocols, even if it meant fewer reprinted papers in the volume. But perhaps those files are for the historians, rather than an autobiographical volume.

Charles G. Gross is in the Department of Psychology, Princeton University, Green Hall,

Princeton, New Jersey 08544-1010, USA.

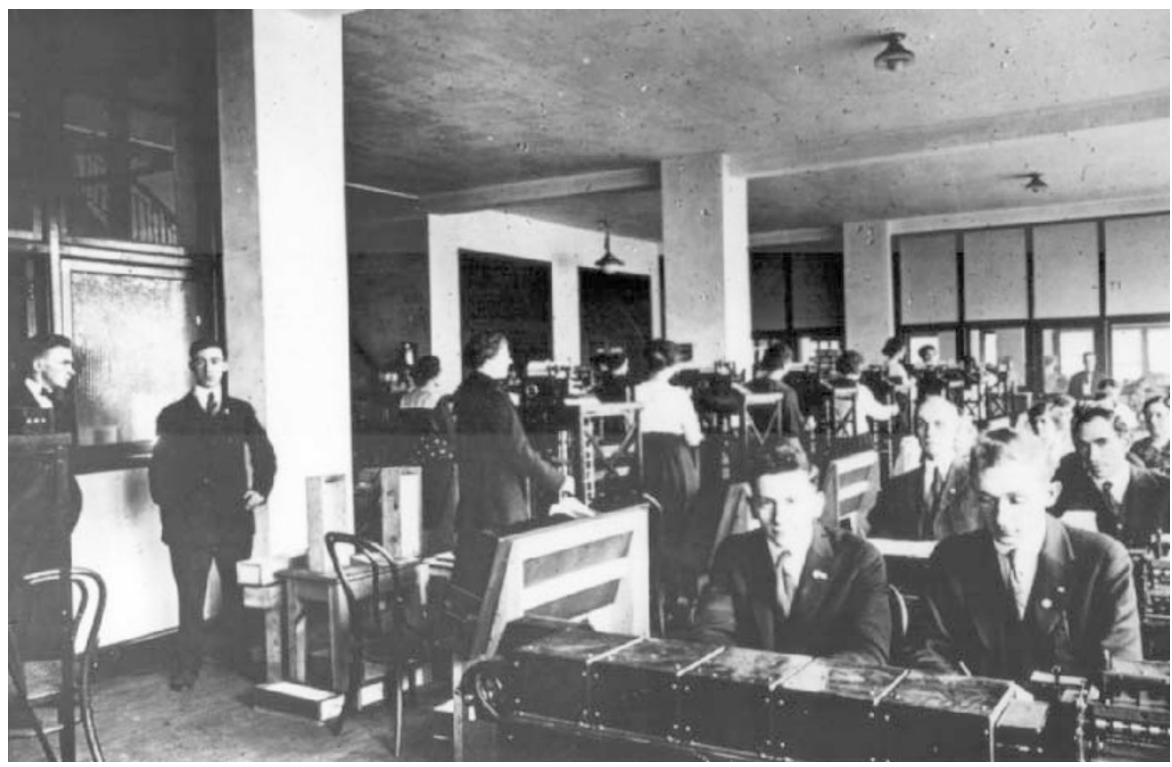

Crunch time: large numbers of people used to do the calculations now done by electronic computers.

\section{Recovered history}

When Computers Were Human

by David Alan Grier

Princeton University Press: 2005. 412 pp.

$\$ 35, £ 22.95$

\section{Jon Agar}

We work from morn till night,

For computing is ourduty;

We're faithful and polite,

And our record book's a beauty;

With Crelle and Gauss, Chauvenet and Peirce,

We labor hard all day;

We add, subtract, multiply and divide,

And we never have time to play.

(from The Observatory Pinafore by Winslow Upton, 1879)

Human computers certainly did work hard all day, and had the aches and pains to show for it: elbow joints inflamed from cranking calculator handles, or fingers and thumbs cramped from pencilling figure after figure on to graph paper. For two centuries the modern scientific enterprise was built on their efforts. Yet every time a logarithm was looked up, or the value of a Bessel function checked, a debt was incurred that was rarely acknowledged. And now the human computer has vanished from history.

People do not disappear from our collective memory by accident. Forgetting is not a passive process: people are forgotten for a reason. Two decades ago, the sociologist Steven Shapin noted pointedly that the lab technician, although essential to making an experiment work, rarely appeared in accounts of successful scientific work. But if something went wrong, the finger was pointed at human interference. Erasing the human hand was part of the means by which an experiment was seen to reveal aspects of nature, rather than aspects of society.

David Alan Grier's recovery of the wonderfully rich story of human computers not only allows us to repay a debt, but also to ask why human computers were made to disappear in the first place. They were drawn from the margins of the scientific establishment. Many were women. Nicole-Reine Lepaute, for example, the well-to-do wife of a royal clockmaker, was one of a trio - said to be the first astronomers to divide the labour of scientific calculation - who calculated the orbit of Halley's comet in time for its perihelion of 1758. Many later female computers came from much poorer backgrounds.

Male computers, too, were relatively disadvantaged. Many of the computers employed in Gaspard de Prony's Bureau du Cadastre, a factory of calculation, were hairdressers and wigmakers who had fallen on hard times following the French Revolution. Often the reason was financial: women, boys and immigrants made for cheap and willing labour. It was even said of Harvard Observatory, run by the relatively progressive Edward C. Pickering and staffed by college graduates, that the "computers are largely women who can be got to work for next to nothing".

By the Second World War, the heyday of human computers, they were routinely referred to as 'girls'. Indeed, managers calculated 'girl-years' of effort, and even defined the 'kilogirl', a unit for measuring work. But, as Grier emphasizes, "even at this date, computing was not the sole domain of women. It was really the job of the dispossessed, the opportunity granted to those who lacked the financial or societal standing to pursue a scientific career." For computing offered people from the margins an entry into the scientific world - an opportunity that they often grasped with both hands.

It is notoriously difficult to recover details 